XIV. Ueber das beständige Erscheinen con Licht am negatioen $P_{0}$ der Volta'schen Süule; oon Hrn. Abt Moigno.

(Compt. rend. T. XXX. p. 359.)

A Im 9. Dec. 1846 übersandte ich der Akademie d. Wissenschaften eine Abhandlung, betitelt: Abhandlung über die Versuche des Dr. Neef und über die allgemeine Theorie des Lichts, der Wärme und der Elektricität. Ich habe zu Frankfurt dic bübschen, genauen und überzeugenden Ver. suche des gelehrten Doctors gesehen '); für mich, wie für ihn, war es bewiesen: 1) dals das Licht immer am negativen Pol erscheint und dieses primitive Licht unabhängig von der Verbrenuung ist; 2) dafs die Quelle der Wärme eigentlich der positive Pol ist und diese Wärme ursprünglich eine dunkle ist; 3) dafs Licht und Wärme bei ihrem Entstehen nicht zusammenfallen, sondern uur, vachdem sie auf einen gewissen Grad gesteigert worden sind; aus dieser Verschmelzung entstehen die Phänomene der Flamme und der Verbrennung.

In den Comptes rendus ward blols der Titel meiner Abhandlung gegeben, und von den schönen Versuchen des Hrn. Neef war darin erst die Rede, nachdem auch Hr. Matteucci sich mit dem Gegenstande beschäftigt und darüber der Akademie zwei Notizen übersandt hatte.

Die fast ausschliefsliche Erzeugung von Wärme am positiven Pol darf nicht in Zweifel gezogen werden; sie ist tuberall einleuchtend, z. B. bei dem kleinen Apparat des Hrn. De la Rive, wo man zwei in scharfe Kegel auslaufende Eisencylinder, die unit den beiden Polen der Säulc verbunden sind, vor einander bringt. Man versichert sich mit den blofsen Fingern, dafs das mit dem negativen Pol verbundene Eisen noch kalt ist, während das positive Eisen schon sehr heils ist.

Die Entstehung des Lichts an negativen Pol ist eben1) Vergl. Ann. Bd. 66, S. 414 und Bd. 69, S. 141. 
falls eine unzweifelhafte Thatsache, welche mich oft uberrasclut hat. Wir habeu sie bei Hru. Rumkorff in grofsem Maafsstabe gesehen. Mau brachte in das Vacuum zwei Platiukugeln als Pole eines Inductionsstroms, der mittelst eines Masson'schen Rades erregt worden, und man sah deutlich, dafs eine der Platinkugeln leuchtend und relativ kalt war; bald war es die eine, bald die andere, je nach der Kichtung des Stroms, und berücksichtigte man die Unkehrung des Inductionsstromes, so ergab sich der Neef sche Satz als richtig. Die negative Kngel war die leuchtende und relativ kalte, die positive dagegen die dunkle und relatio warne.

Am letzten Montag, den 7. Januar (1850), haben wir diese bewunderswürdige Vertheilung von Licht und Wärme unter neuen und noch auffallenderen Umstănden bestätigt gesehen. Hr. Jules Dub o s c q, Zogling and Schwiegersohn des Hrn. Soleil, prufte einen neuen Moderator und Fixator des elektrischen Lichts, indem er vor einer grofsen Zahl von Zuschaueru die Fundamental-Versuche der $O_{p}$ tik damit wiederbolte. Fonf bis sechs Mol bintereinander liefs ich den Strom durch Entfernen der Kohle unterbrechen und durch Nabern wieder herstellen. Bei jedem neuen Contact zeigte sich das ursprünglich weifse Licht auf der Kohle am negativen Pol. Allein bald nach Wiederherstellung des Stroms begann die Verbrennung an positiven Pol. Die an diesem Pol befindliche Kohle holte sich aus, unter Aussendung eines weit glänzenderen Lichtes als das vom negativen Pol, wie es schon die HH. Fizeau und Foucault nachwiesen. Vierzehn Tage nachber wiederholte ich diesen Versuch vor Hrn. Séguier mit gleichem Erfolg; stets erschien das Licht am negativen Pol zuerst. Diese Thatsache schien mir recht merkwordig und ich glauble daber sie der Akademie bemerklich machen zu müsen. Auf diese Bemerkung verfiel ich zuerst, als ich balf bei den grofsartigen Versuchen eines ihrer Mitglieder, des Hrn. Despretz, dem ich sie mittheilte, und mit dem ich sie sogar prifte, obne sie jedoch zu vollenden. 
Schliefslich sey mir erlaubt hinzuzufügen, dafs der Moderator und Fixator des Hrn. Jules Duboscq durchaus nichts zu wünschen übrig lälst. Selbst durch eine Linse hin, deren man sich bediente, um die Interferenzlinien der Fresnel'schen Spiegel zu projiciren, blieben die Schwankungen des elektrischen Lichts unmerklich.

\section{Reclamation in Betreff einer Beobachtung beim Leidenfrost'schen Phänomen.}

In

n einem Briefe vom 10. Juni d. J. macht Hr. Dr. R udolph Bottger in Frankfurt a. M. mich darauf aufmerksam, dals die kürzlich von Hrn. J. Schnaufs in diesen Annalen (Bd. 79, S. 432) beschriebene Erscheinung der stervförmigen Gestalt eines dem Leidenfrost'schen Versuch unterworfenen Tropfens schon längst von ihn beobachtet und veröffentlicht worden ist, sowohl 1838 in seinen "Beiträgen zur Physik und Chemie, Heft I. S. 50, als auch und zwar früher, schon 1837, in Erdmann's Journ. der Chemie, Bd. X, S. 108. Allerdings ist dem so und ich bedaure, dafs es ubersehen worden ist, aber andererseits wird doch, glaube ich, jeder Verdacht eincr Absichtlichkeit hiebei sogleich fortfallen müssen, wenn man die beiderseitigen Beobachtungen etwas näher vergleicht. Es zeigt sich nämlich, dafs sie in einem nicht unwesentlichen Punkt direct auseinander gehen, denn während der geehrte Frankfurter Physiker die Zahl der Strahlen oder Vorsprünge der Figur zu $5,7,9,11$ oder 13, mithin als ungerade angiebt, sagt $\mathrm{Hr}$. S. ausdrücklich, dafs sie stets eine gerade sey, was ich auch in Betracht der wahrscheinlichen Entstehung der Figur für das Richtige halten möchte.

P.

Gedruckt bei A. VV. Schade in Berlin, Grünstr. 18. 